\title{
Managing chest pain patients in general practice: an interview-based study
}

Leen Biesemans ${ }^{1 \dagger}$, Lotte E. Cleef ${ }^{2 \dagger}$, Robert T. A. Willemsen ${ }^{2^{*}+}$ (D), Beatrijs B. N. Hoorweg ${ }^{2}$, Walter S. Renier ${ }^{1}$, Frank Buntinx ${ }^{1,2}$, Jan F. C. Glatz ${ }^{3}$ and Geert-Jan Dinant ${ }^{2}$

\begin{abstract}
Background: Assessment of chest pain in general practice is challenging. General practitioners (GPs) often feel uncertainty when dealing with chest pain. The role of new diagnostic tools is yet unclear.

Therefore, we aimed to learn: (1) whether or not GPs experience a change in incidence and presentation of chest pain, (2) how GPs deal with uncertainty, and (3) which thoughts, demands and doubts concerning new diagnostic tools occur.

Methods: Semi-structured, face to face interview based study, aiming at six main subjects: experienced changes in prevalence of chest pain, the management of chest pain patients, dealing with uncertainty, the GPs' approach in referring chest pain patients, GPs' attitude towards 'unnecessary' referrals, and the GPs' suggestions for improving the management of chest pain patients.

Results: 145 GPs in Belgium and the Netherlands were invited to participate, 27 (15 Flemish and 12 Dutch) GPs were interviewed. Data saturation was reached. The number of patients having an acute coronary syndrome among chest pain patients is decreasing, whereas the presentation of atypical complaints increases, together leading to more uncertainty. GPs rely on their own judgment above all, and desire new diagnostic tools only when these tools are of proven added value.

Conclusion: The incidence of chest pain in general practice is not decreasing according to the GPs. However, the presentation of chest pain is changing. GPs feel relatively comfortable with referring a considerable number of chest pain patients without ACS, as over-referral is safe. Uncertainty is regarded as a substantial element of their profession. New diagnostic tools are awaited with cautiousness.
\end{abstract}

Keywords: General practice, Cardiovascular disorders, Diagnostic tests, Urgent care, Risk assessment

\section{Background}

\section{Chest pain in general practice}

In general practice, chest pain as a reason for encounter is common (prevalence 1-3\%) and differential diagnosis is broad $[1,2]$. Yet, in only a minority, an acute life threatening disease is concerned. Severe diseases as acute coronary syndrome (ACS), pulmonary embolism or thoracic aortal dissection are outnumbered by non-urgent causes as gastro-esophageal reflux disease (GERD) or thoracic wall pain $[1,3,4]$. However, discriminating between ACS

\footnotetext{
* Correspondence: robert.willemsen@maastrichtuniversity.nl

†Leen Biesemans, Lotte E. Cleef and Robert T. A. Willemsen contributed equally to this work.

${ }^{2}$ Department of Family Medicine, Maastricht University, P. Debyeplein 1, (PO box 616), Maastricht 6200, MD, the Netherlands

Full list of author information is available at the end of the article
}

and less severe causes of chest pain, based on clinical findings or electrocardiography, is difficult [5-8].

The challenge of (not) referring patients with chest pain Most guidelines clearly state that general practitioners (GPs) should refer every patient suspected of an ACS to secondary care facilities as soon as possible, or GPs should even be bypassed to prevent loss of time and, consequently, myocardial cell necrosis [9]. However, for every chest pain patient with a life threatening disease as ACS, a GP encounters 11 patients with chest pain of a non severe cause [1]. Therefore, clinical judgement and triage by GPs remains inevitable to prevent unnecessary referrals and to keep the burden on secondary care facilities acceptable $[3,10]$. To reach this goal, GPs compromise

(c) The Author(s). 2018 Open Access This article is distributed under the terms of the Creative Commons Attribution 4.0 International License (http://creativecommons.org/licenses/by/4.0/), which permits unrestricted use, distribution, and reproduction in any medium, provided you give appropriate credit to the original author(s) and the source, provide a link to the Creative Commons license, and indicate if changes were made. The Creative Commons Public Domain Dedication waiver (http://creativecommons.org/publicdomain/zero/1.0/) applies to the data made available in this article, unless otherwise stated. 
between adequate detection of severe disease on the one hand and reassurement in cases of worried patients with no or mild underlying disease on the other hand $[6,11,12]$. Over time, GPs seem to have found an optimum. They refer only a minority of chest pain patients, thereby adequately maintaining their gatekeeping role. Still, a considerable number of patients with chest pain (approximately 20-40\%) are referred for safe exclusion of ACS, whereas only one out of five of these referred patients suffer from severe disease $[1,13,14]$. Besides classical clinical findings, GPs use gut feeling and background knowledge of their patients to make these challenging referral decisions [15].

\section{Uncertainty when dealing with chest pain}

Notwithstanding this strategy to work with low thresholds for referral to maintain the number of missed cases of ACS low, uncertainty among GPs has been a part of dealing with chest pain in general practice for decades [16-18]. GPs regard guidelines as only partially solving their dilemmas in assessing chest pain patients and as suboptimally answering their questions whether or not to refer these patients [16]. As a possible consequence, guidelines do not integrally lead to behavioural change [19]. Besides, referring patients without consultation for example based on a typical pattern presented in a phone call, as is advertised in cases of suspected stroke - is impracticable in cases of chest pain due to the broad differential diagnosis [20]. Cautious GPs that are anxious about the consequences of missing severe disease refer more often to secondary care facilities, especially when working in out of office hours services [21, 22]. Especially during consultations during out of office hours, maintaining a threshold for referral is challenging [17].

\section{Developments in the field of chest pain in general practice}

Several developments in the field of chest pain in general practice have been described. First, an altering presentation of ACS in general practice has been reported, whether or not due to sex differences in presentation [5, 23-25]. Second, incidence of ACS among chest pain patients in general practice seems to be declining over the years (from approximately $20 \%$ to less than $10 \%$ ), mortality has decreased strongly, and prognosis has improved [1, 26, 27]. Besides absolute data on this topic addressed in quantitative studies, a GP's perception of a possible changing incidence of ACS is important, since a GP's estimation of the probability of an ACS when assessing patients presenting with chest pain (the 'pre-test probability') is influenced by this perception [28, 29]. Third, several diagnostic studies have recently evaluated the role of new diagnostic tools - e.g. clinical decision rules (CDRs) and point-of-care tests (PoCTs) - in managing chest pain patients. GPs in Europe desire a PoCT especially in the field of patients presenting with chest pain [30]. However, a CDR safely reducing referrals is lacking [31].

\section{Objectives}

Studies on GPs' contemporary perceptions, attitudes and experiences in dealing with chest pain patients regarding uncertainty and developments in presentation, incidence and diagnostic tools as described above are mainly dealing with specific diseases, are focussing on out of office hours working situations or are lacking $[16,17,32]$. Therefore, in our study, we aimed to explore the following topics:

(1) Do GPs experience a changing incidence and presentation of chest pain and / or ACS in daily practice, and if so, what changes do GPs observe?

(2) Which considerations are important to GPs and how do they deal with uncertainty (regarding referrals of patients without a life threatening disease as well as missed cases of severe disease) in the management of chest pain patients?

(3) Which thoughts, demands and doubts concerning new diagnostic tools can be extracted from GPs' reflections on managing patients with chest pain? (This final question was addressed only in the Dutch interviews, since most Flemish GPs have no experience with such tools).

\section{Methods}

\section{Inclusion}

145 GPs were selected from a list of GPs who had indicated earlier they were interested in participating in scientific studies. We invited 15 Flemish GPs by phone and 30 per e-mail. 100 Dutch GPs were invited per e-mail and were phoned shortly afterwards to inquire possible participation. We included general practitioners willing to participate, with at least 5 years of working experience. No further selection criteria were used.

\section{Interview}

The semi-structured face-to-face interview, composed by the Flemish researchers, consisted of five main subjects to answer the objectives of the study: (1) recently experienced changes in the prevalence of chest pain and ACS, (2) management of chest pain patients in daily practice, (3) dealing with uncertainty, (4) the GPs' approach in referring chest pain patients, and (5) their attitude towards - in the light of the final diagnosis - 'unnecessary' referrals. The second subject (2) was approached by letting the GPs imagine a chest pain patient and thereby reflect on their diagnostic steps and decision to refer. An additional subject was added in the Dutch interview: (6) the GP's own suggestions for improving the management of chest pain patients in general practice. The interview protocol was 
piloted with a Flemish and a Dutch GP who both had over 25 years of working experience. Flaws were discussed by the researchers and two GPs, which resulted in an adapted version of the interview. The pilot interviews were not included in the final research sample. The main questions, used as starting points of different phases of the interview are given in Additional file 1. Additional questions were not predefined, further answers and themes were initiated by the GPs themselves. The interviews took place at the GPs' practices, incidentally in a GP's private home.

\section{Data collection}

Data were collected through face-to-face interviews. Flemish interviews were carried out by LB, as part of her research thesis completing her GP education, between June and October, 2015. Dutch interviews were carried out by $\mathrm{LC}$ and $\mathrm{BH}$, both fulfilling their research internships during the master phase of their medical school, between April and June, 2016. All interviews were audio-recorded and transcribed verbatim. Data were collected until saturation was achieved. Saturation was defined as the identification of no new nodes in the last two interviews in the Flemish, or the Dutch part of the study, respectively.

\section{Data analysis}

Thematic analysis was used to bring forth answers to the main objectives of this study. All Flemish interview transcripts were analysed independently by two researchers in a process of inductive line-by-line coding. LB coded all transcripts, and four GP residents and one anesthesiology resident coded three transcripts each. Afterwards, differences were discussed and further analysis was assisted by FB and WR. Thereafter, the initial codebook was established, which was adjusted after every four interviews. In a second step the codes were refined, resulting in the development of descriptive themes. Finally, a thematic analysis was performed by all researchers to generate new analytical themes.

Each Dutch interview was analysed and coded independently using the Flemish codebook by $\mathrm{LC}$ and $\mathrm{BH}$. Conflicts were solved by discussion. During the analysis of subsequent interviews, the initial code list was further refined by adding new codes under the pre-existing themes, when confronted with relevant data that could not be linked to an existing code. Finally, a framework analysis was performed by $\mathrm{LC}, \mathrm{BH}$, and $\mathrm{RW}$ to generate new hypotheses. Ultimately, Flemish and Dutch results were independently analysed and discussed by LB, LC and RW to uncover similarities and differences in outcomes. Subsequently, these findings were documented when applicable in the results section of this paper. NVivo 11 pro software was used to facilitate coding.

\section{Ethics}

All participants were informed about the aims of the study and the recording of the interviews. The study was approved by the Medical Ethical Committees of the University of Leuven and of Maastricht University.

\section{Results}

145 (45 Flemish, 100 Dutch) GPs were invited to participate, 27 GPs (15 Flemish and 12 Dutch) were interviewed. The main reason for declining our invitation was a lack of time. GP characteristics are presented in Table 1. During the interviews, all GPs commented extensively on the questions concerning this study's main three objectives. All interviews lasted 45 to $60 \mathrm{~min}$, incidentally an interview lasted $75 \mathrm{~min}$.

\section{Incidence and presentation of chest pain in general practice (objective 1)}

Most GPs stated that they are confronted with chest pain at least once every week. Chest pain can have a wide variety of causes, of which the majority is not of cardiac origin.

"Hm, I think we are confronted with this complaint weekly, maybe even multiple times a week." [NL GP 12]

Table 1 Characteristics (gender, age, years of experience, type and area of practice) of the participating GPs

\begin{tabular}{|c|c|c|c|c|}
\hline & & Dutch & Flemish & Total \\
\hline \multirow[t]{2}{*}{ Gender } & Male & 8 & 10 & 18 \\
\hline & Female & 4 & 5 & 9 \\
\hline \multirow[t]{7}{*}{ Age groups } & $35-39$ & 1 & 2 & 3 \\
\hline & $40-44$ & 4 & 0 & 4 \\
\hline & $45-49$ & 0 & 4 & 4 \\
\hline & $50-54$ & 1 & 2 & 3 \\
\hline & $55-59$ & 5 & 2 & 7 \\
\hline & $59-65$ & 1 & 4 & 5 \\
\hline & $>65$ & 0 & 1 & 1 \\
\hline Years of experience & & $20.6(2.5-36)$ & $26.7(10-40)$ & $24.0(2.5-40)^{a}$ \\
\hline \multirow[t]{3}{*}{ Type of practice } & Single & 4 & 4 & 8 \\
\hline & Duo & 5 & 4 & 9 \\
\hline & Group & 3 & 7 & 10 \\
\hline \multirow[t]{2}{*}{ Area of practice } & Urban & 8 & 6 & 14 \\
\hline & Rural & 4 & 9 & 13 \\
\hline
\end{tabular}

Through purposive sampling we aimed to attain a heterogeneous group, including both female and male GPs, GPs working in both rural and urban regions and in single, duo and group practices. One participating GP had only 2,5 years of experience. Yet the data derived from this interview were maintained, since these were in line with the data from the more experienced GPs. Single, duo, group practices refer to GP practices managed by respectively one, two and more GPs. Abbreviations: GP general practitioner, $N$ number. ${ }^{\mathrm{a}}$ Mean followed by the range in brackets 
"Yes, the lion's share here, of people presenting with chest pain, is not of cardiac origin." [NL GP 8]

Although some Dutch GPs experienced an evident increase in the prevalence of chest pain in their practice, the majority of GPs did not experience a change in frequency over time. However, most GPs experienced a change in the clinical spectrum of chest pain. GPs claimed to encounter less cases of ACS, due to improved cardiovascular risk management in general practice, and more atypical thoracic complaints, due to a growing awareness on chest pain in the general population. The anxiety accompanying this awareness, combined with the continuously available health care in large out-of-hours general practice facilities, lower the threshold to consult a GP.

"Then I think it is more or less the same ... if you don't only count cardiac but also other types of chest pain like respiratory infections or indeed psychosomatic symptoms. Then I think it [the frequency of chest pain] is comparable to before." [BE GP 4]

"I think that the frequency with which we see a grave acute infarction nowadays is a lot lower than it was twenty years ago." [BE GP 7]

Most GPs believed raising awareness in the general population on the possible consequences of chest pain is important. However, Dutch GPs stated it can result in an increase in patient anxiety, leading to more uncertainty and consultation of a GP.

"Of course raising public awareness is helpful, but it can also cause more unnecessary consultations. Not everyone is good at assessing their own situation. And people are worried when they feel something." [NL GP 12]

Especially in out-of-hours general practice facilities in the Netherlands, new triage guidelines with a low threshold for directly sending out an ambulance in case of chest pain, are causing Dutch GPs to encounter less chest pain patients. Some Flemish GPs stated that recently more patients go directly to the emergency room, especially in urban areas with a high number of immigrants.

"Outside office hours people often call, saying: "I experience an acute severe pressure on my chest", and according to the current guidelines, the ambulance will leave for this patient. In such case we don't assess the patient ourselves." [NL GP 8]

"We have a varied patient population here. We are on the verge of a rural area where most people still obediently go to the GP. On the other hand, in the city of Mechelen e.g., the citizens - and certainly the immigrants - go to the emergency department much easier and will thus pass us by." [BE GP6]

\section{Assessment of chest pain and dealing with uncertainty (objective 2)}

When confronted with a chest pain patient, GPs quickly attempt to distinguish between acute and non-acute pathology. The most important tools in assessing chest pain are history taking, clinical evaluation and gut feeling. The language used by GPs suggests a feeling of responsibility.

"Yes, you first try to determine in which framework the pain fits. (...) Are the lungs causing the problems, or is it the heart or is it something less serious? So that's what you try to assess first and foremost." [BE GP10]

"But I taught myself, if I have a certain gut feeling that something isn't right, yes, then I just refer them. I'm not going to take the risk behind the patient's back." [NL GP 11]

Most GPs questioned the value of diagnostic tools such as ECG or troponin in ruling out ACS at first assessment. However, a few GPs felt confident enough to not refer a patient based on a negative ECG. In non-acute situations, these diagnostic tools are mostly used to take away any doubt, experienced by the GP, and to reassure the patient. GPs regard personal judgment, not advanced diagnostic tools, as the main instrument to rely on.

"Especially because you have to assess the value of an ECG. I mean that an ECG can be negative despite the fact that the clinical presentation is very suspicious. Then you have to follow your clinical judgment. The technicalities can be an affirmation of your clinical assessment but not vice versa." [BE GP8]

"It also helps to reassure people that are not expected to have a serious condition, then you'll have an additional confirmatory tool [ECG]." [NL GP 12].

When a patient is suspected of ACS, GPs immediately refer them to the emergency department, transported by ambulance with the highest level of urgency.

"But when someone has acute chest pain suspected of ACS, that goes with getting picked up by an ambulance with the highest urgency." [NL GP 8].

Some GPs considered it acceptable for a patient to leave for the hospital on their own, if the patient is in a 
stable condition. However, they should never drive themselves.

"Or it is a semi-acute problem and the person can go to the hospital by their own means of transportation, transported by someone else. They shouldn't drive themselves." [NL GP 2]

Before the ambulance arrives, some GPs administer medication and accomplish intravenous access. However, a few Flemish GPs felt insecure about their knowledge on acute interventions and their necessity in urgent situations.

"Imagine if you had to suddenly give an injection urgently: (...) If you haven't done any of that in twenty years, or haven't received any information about it anymore, you won't start doing it again that easily, right?" [BE GP10]

When patients call their GP because of chest pain and their situation seems to be unstable, it depends on the amount of time available, whether the GP heads to the patient himself, sends an ambulance directly, or does both.

"Unless I have to drive for fifteen minutes, some of our patients live quite far off, and I am really busy with other obligations. But in principle I do both [send an ambulance and leave for the patient]." [NL GP 2]

In non-urgent cases patients are referred to the hospital cardiology department for a consultation on a following day.

To GPs, the greatest difficulties in the assessment of chest pain are atypical symptoms, expressed - according to Dutch GPs - mainly by women.

"Because a woman often has atypical complaints regarding cardiovascular conditions. You have to be more careful, which means you maybe have to look a little closer." [NL GP 7]

Some GPs feel the need to refer anxious patients, for their own and the patient's peace of mind.

"I think when people keep consulting you with a certain complaint, not just chest pain, even if they have already consulted you about this complaint earlier, that's an indication to refer the patient anyway." [NL GP 2]

In urgent cases, most GPs feel no insecurity in choosing to refer a patient or not. However, when GPs experience uncertainty, it is mainly due to doubt as to which condition is causing the chest pain, sometimes leading to more referrals.
"But my rule is: when I'm uncertain, I always refer the patient.” [NL GP 10]

In less urgent cases some GPs try to perform most diagnostics themselves, start a test treatment, or opt for the approach of watchful waiting, to make a more targeted referral.

"Yes, I try to rule out some things myself, those things that are really easy to rule out. (...) And subsequently, because of these possibilities, you refer less often."

[NL GP 10]

To diminish uncertainty, GPs stated they could consult colleagues or a cardiologist. However, not all GPs feel the need to do so. Mainly Flemish GPs stated they rarely ask for advice on managing chest pain patients.

"I think that we are in a luxury position because we work here with three GPs in a group. There is always someone you can immediately ask for a second opinion. That helps a lot. A short discussion is often enough to be able to make a decision." [BE GP5]

Sometimes, uncertainty remains after a consultation with a chest pain patient. To reduce this uncertainty, some GPs tend to refer more patients.

"Yes, if you have a feeling that you've made a mistake somewhere or that you've misjudged something it certainly keeps...lingering in your head for a while, keeps bothering you for a while." [BE GP14]

Afterwards, some GPs like to debrief cases they were uncertain about, both on medical and personal aspects, either through the cardiologist's letters or through discussion with colleagues. However, some Flemish GPs find it difficult to find a safe environment to talk about their uncertainty.

"It helps me that I can debrief about it ... eh ... in a safe environment. I think that that is one of the most important things a GP - and actually any doctor can attain: safe situations. I've been working now for twenty years and I have finally found safety. (...) I think that that's important for every doctor, that he has the opportunity to talk about his uncertainties with his peers." [BE GP1]

Nonetheless, all GPs believed that insecurity and mistakes are part of their profession and that GPs must learn to handle these situations. Most GPs believed they became more confident in assessing chest pain during their career, due to experience and development of their 
gut feeling, causing them to refer less patients unnecessarily. Still, GPs stated they refer quite a large part of chest pain patients because they do not want to risk missing ACS. Looking back after obtaining the final diagnosis, some of these referrals were unnecessary. However, GPs believed this is due to a lack of diagnostic tools to initially rule out ACS. Critical incidents of missing ACS cause GPs to be more cautious, either temporarily or permanently. GPs judge their referral decisions as right or wrong in the light of a final diagnosis. This is remarkable, since a referral decision based on considering a severe disease can essentially not be wrong.

"I think the experience and the development of the gut feeling plays a role in becoming more confident. So, I think that I was more insecure 15 years ago, and because of that I may have referred more patients wrongly." [NL GP 2]

"It is like that, when you get a claim or you think: "Oops, did I miss that?" then you will pay more attention to those complaints for a period of time. Absolutely." [NL GP 5]

"Sometimes you have to make a risk assessment. Sometimes you are right and sometimes you are wrong. But there's no dishonour in that. I would rather refer one patient too many than one too few. Because then you are going to have to come up with a really good explanation." [BE GP3]

Referrals of patients that eventually appear to have no severe disease can be unfavourable, leading to high health care costs, an overload of the hospital staff and a stressful experience for patients. However, some GPs never let their referral decision depend on such possible thresholds. Others stated they try to prevent medicalisation and somatisation in low-risk patients. GPs sometimes get criticised on their referral decisions by hospital physicians. Most GPs claim not to be affected by this criticism, however, their language to express their feeling of making autonomous referral decisions is rather explicit. Thus, GPs seem to define their position in a difficult field where colleagues and patients might judge the GP's decisions.

"I have assessed the patient, so I have to take responsibility and I have to make the decision on my own." [NL GP 1]

“That is your autonomous decision. He wasn't there at the moment you called. And if you say in that moment 'I want an emergency doctor here', then it has to be there, end of story! Ten minutes later, the situation is different, the insight is different, the patient is different and so on. And then maybe the decision would be different. But they can never judge you for that!" [BE GP 1]

\section{Thoughts, demands, and doubts concerning new diagnostic tools (objective 3 )}

Most GPs stated they are satisfied with the current diagnostic options for chest pain patients in general practice and some believe that clinical assessment will remain the most important tool in assessing chest pain patients. Others do believe an additional diagnostic tool such as a biomarker PoCT would be useful. Yet, usability strongly depends on indications and diagnostic accuracy. A few Dutch GPs suggested to combine such test with a clinical decision rule. In general, new diagnostic tools are considered to be of a certain degree of added value, with a remaining central role for clinical judgment by the GP.

"Look, if you just... Independently of what it says, and I think the patient's situation is not looking good based on the clinical assessment, then I'll refer him anyway. Then I don't let it depend on a biomarker." [NL GP 12]

"It $[\mathrm{PoCT}]$ might contribute something in case of doubt. Then of course it also depends on the sensitivity and the cost price. You have to be quite sure when you use such a thing and it comes out positive, that you won't make big effort which in the end turns out to be futile." [BE GP8]

"If a clinical decision rule will be designed (...) those are really helpful. You count the points and then you get yes, no, or an intermediate. Yes, if you add a troponin test to that (...) then I think it will contribute of the quality of health care." [NL GP 8]

\section{Discussion}

\section{Summary of main findings}

First, when suspecting an ACS, GPs base their suspicion mainly on history taking and gut feeling. Second, recent findings in literature are endorsed by the interviewed GPs: chest pain is still a common reason for consulting a GP, the relative number of ACS patients among chest pain patients seems decreasing, whereas the presentation of atypical complaints increases, leading to more uncertainty. Third, GPs compensate for the experienced feeling of uncertainty by referring patients, performing additional tests or discussing cases with colleagues. Besides, GPs regard uncertainty as a substantial part of their profession and they feel more certainty when 
working experience increases. Still, some GPs use explicit language to express their certainty, possibly reflecting an ongoing struggle to keep patients and colleagues in secondary care satisfied. Overall, GPs feel relatively comfortable with a certain degree of over-referral of chest pain patients, as over-referral is regarded as a safe strategy in dealing with a potentially life threatening condition. An ongoing and substantial role for clinical judgment by the GP is expected. Fourth, new diagnostic tools in general practice are anticipated with cautiousness. Proper clinical embedding of such tools is obligatory according to the interviewed GPs.

\section{Strenghts and limitations of the study}

Before interviewing the GPs, an extensive tryout of the interview with an experienced GP, observed by another experienced GP, was carried out. Two pilot interviews were performed. All Flemish interviews were carried out by LB, a GP in training. Her own experience from working in general practice might have had an impact on the interviews. There might have been bias due to her own opinion on subjects that were discussed. On the other hand, her own learning process as a GP might have lead to a curious attitude. The Dutch interviews were carried out by $\mathrm{LC}$ and $\mathrm{BH}$, both master's students in medicine. They had no experience in managing chest pain patients themselves, possibly leading to a certain degree of open-mindedness although the lack of experience could have prevented them from thinking of all possible in-depth questions.

The population of interviewed GPs contained a good variety in area, type of practice and age (Table 1). They might represent a selection of GPs more than averagely interested in chest pain, although we did not find any evidence for such selection bias. Moreover, a selection of interested GPs would lead to an underestimation of experienced uncertainty, rather than an overestimation. Our study population consisted of more men $(n=18)$ than women $(n=9)$. However, differences of the answers between sexes or years of experience as a GP were not observed. All participating GPs seemed motivated to respond extensively to our questions. Theoretical data saturation was reached in the Flemish and Dutch interviews separately.

\section{Further findings and comparison to existing literature}

The incidence of chest pain in general practice has not changed remarkably. However, most GPs do experience a change in the clinical spectrum of chest pain, encountering less cases of ACS, and in its presentation. These findings are in line with various epidemiological studies, although data of these studies were partially obtained in a hospital setting [26, 27]. The GPs attribute these changes primarily to better prevention and treatment strategies. Additionally, GPs find that there are more atypical presentations of chest pain, due to the growing awareness of the possible causes of chest pain in the general population. This causes chest pain patients to worry and consult their GP more often. Dutch GPs state that the prevalence of atypical chest pain in women has increased over the years, possibly due to the growing awareness on this subject, and find the management of these patients challenging. Women indeed present with atypical chest pain more often than men, but more research on the possibly different pathophysiology in women and men is needed, in order to reveal the relevance of the differences in presentation [25]. Both Dutch and Flemish GPs reported that, in recent years, more patients go directly to the emergency room.

GPs' judgment of chest pain is based mainly on history, physical examination and gut feeling. Indeed, it is known that GPs use additional tools for assessment, such as background knowledge about patients and gut feeling [15, 33]. Most GPs question the value and applicability of currently available diagnostic tools such as ECG and troponin in the assessment of chest pain. However, some GPs do use them to take away doubt or to reassure the patient. When there is a strong suspicion of ACS, GPs immediately refer the patient to the emergency department. Although most GPs agreed that transportation by ambulance with the highest level of urgency is appropriate, some GPs send stable patients to the hospital by their own means of transport, which is debatable [34]. Before the ambulance arrives, GPs sometimes administer medication and accomplish intravenous access. However, several Flemish GPs are reluctant to do this, doubting their ability to perform these interventions. Studies on this subject are scarce. A cross-sectional study from 2008 showed that a training program for GPs on interventions for ACS could improve the pre-hospitalization care of these patients [35].

GPs sometimes experience uncertainty in the management of chest pain patients, during or after the consultation. GPs tend to reduce this uncertainty by easily referring patients or performing additional tests. Some GPs consult their colleagues or a cardiologist to diminish uncertainty, though mainly Flemish GPs rarely ask for advice on managing chest pain. When uncertainty persists after the consultation, most GPs seek confirmation either through the cardiologist's letters or through discussion with colleagues. GPs overall become more confident in assessing and managing chest pain patients during their career.

GPs mainly feel comfortable with their diagnostic assessment, management and possible over-referral of chest pain patients, stating that sometimes referral is necessary to get confirmation of the diagnosis. For most GPs the unfavourable consequences of 'unnecessary' 
referrals and criticism by secondary care physicians are not influencing their decisions. Several studies indeed indicate that GPs' clinical judgment is quite accurate and that they succeed in managing chest pain patients well $[1,13,36]$. However, the explicit language used when describing their feeling of certainty suggests that GPs are aware of underlying phenomena. These phenomena might be reflections of their strong feeling of responsibility when dealing with possibly life threatening disease and / or might be a consequence of the feeling of being judged by patients or colleagues for correctly referring.

Though most GPs agree that clinical assessment will remain the most important tool in diagnosing chest pain patients, some GPs think that reliable new diagnostic tools (such as PoCTs) could be a useful addition to improve diagnostic accuracy. The general attitude towards such tools seemed more conservative than in recent questionnaire based studies [30, 37]. GPs pointed out that such tools should be reliably embedded in clinical care and is regarded as an additional tool rather than an alternative one making clinical judgments unneeded in the future. Moreover, dilemmas in assessing chest pain patients are thought to partially persist, regardless of future developments.

\section{Conclusions}

- GPs feel that the incidence of chest pain in general practice is not decreasing. However, the number of patients having an acute coronary syndrome among patients presenting with chest pain is decreasing, whereas the presentation of atypical complaints increases, together leading to more uncertainty. Yet, uncertainty is regarded as a substantial element of their profession.

- GPs feel relatively comfortable with referring a considerable number of chest pain patients without ACS, as over-referral is safe.

- New diagnostic tools are awaited with cautiousness: GPs rely on their own judgment, and desire new diagnostic tools only when these tools are of clear added value.

\section{Additional file}

Additional file 1: Semi-structured interview. (DOCX $27 \mathrm{~kb}$ )

\section{Abbreviations}

ACS: Acute Coronary Syndrome; CDR: Clinical decision rule; GERD: Gastroesophageal reflux disease; GP: General practitioner; PoCT: Point of care test

\section{Acknowledgements}

We sincerely thank all GPs who shared their valuable insights, thoughts and doubts concerning chest pain patients with us, in a talkative and open-hearted manner.

\section{Funding}

The research project on chest pain in general practice of RW, FB, GD and JG is funded by means of an unrestricted grant from FABPulous BV, the company that develops point-of-care H-FABP-tests. Part of this grant was provided by the Horizon 2020 SME Instrument (RapidEx666666). FABPulous BV agreed not to interfere with data collection, data management and analysis of data. Publication of possibly unfavorable outcomes of our study was guaranteed. The authors alone are responsible for the content and writing of the paper.

\section{Availability of data and materials}

The datasets used and analysed during the current study are available from the corresponding author on reasonable request.

\section{Authors' contributions}

$L B, L C$ and $B H$ performed the interviews. LB, LC, BH and RW analysed and interpreted all data. All authors contributed to the study protocol and read and approved the final manuscript.

\section{Authors' information}

LB is general practitioner in Bonheiden, Belgium. LC is a graduating medical student at Maastricht University, the Netherlands. RW is general practitioner in Maastricht, the Netherlands. He is specialised in cardiovascular primary care medicine and is a PhD-candidate at Maastricht University. $\mathrm{BH}$ is a graduating medical student at Maastricht University, the Netherlands. WR is general practitioner in Sint-Jans-Molenbeek, Belgium, and researcher at the Department of General Practice of the Catholic University Leuven, Belgium. FB is general practitioner in Maasmechelen, Belgium, and is emeritus professor at the Department of General Practice of the Catholic University Leuven, Belgium and of Maastricht University, the Netherlands. JG is professor of Metabolic Aspects of Cardiovascular Diseases working at the Genetics \& Cell Biology Department of Maastricht University, the Netherlands. GJD is general practitioner in Helmond, the Netherlands, and is professor of Family Medicine at the Family Medicine Department of Maastricht University, the Netherlands.

\section{Ethics approval and consent to participate}

The study was approved by the Medical Ethical Committees of the University of Leuven and of Maastricht University. All participants provided written consent to participate and additional verbal consent was given and recorded at the start of each interview.

\section{Competing interests}

JG is chief scientific officer (CSO) at FABPulous BV. The remaining authors report no conflicts of interest.

\section{Publisher's Note}

Springer Nature remains neutral with regard to jurisdictional claims in published maps and institutional affiliations.

\section{Author details}

${ }^{1}$ Department of Family Medicine, Catholic University Leuven, Leuven, Belgium. ${ }^{2}$ Department of Family Medicine, Maastricht University, P. Debyeplein 1, (PO box 616), Maastricht 6200, MD, the Netherlands. ${ }^{3}$ Department of Genetics \& Cell Biology, Maastricht University, Maastricht, the Netherlands.

Received: 15 January 2018 Accepted: 21 May 2018 Published online: 02 June 2018

\section{References}

1. Hoorweg BB, Willemsen RT, Cleef LE, Boogaerts T, Buninx F, Glatz JF, et al. Frequency of chest pain in primary care, diagnostic tests performed and final diagnoses. Heart. 2017;103:1727-32.

2. McConaghy JR, Oza RS. Outpatient diagnosis of acute chest pain in adults. Am Fam Physician. 2013:87:177-82.

3. Haasenritter J, Biroga T, Keunecke C, Becker A, Donner-Banzhoff N, Dornieden $\mathrm{K}$, et al. Causes of chest pain in primary care-a systematic review and meta-analysis. Croat Med J. 2015;56:422-30. 
4. Buntinx F, Knockaert D, Bruyninckx R, Deblaey N, Aerts M, Knottnerus JA, et al. Chest pain in general practice or in the hospital emergency department: is it the same? Fam Pract. 2001;18:586-9.

5. Hani MA, Keller H, Vandenesch J, Sönnichsen AC, Griffiths F, DonnerBanzhoff N. Different from what the textbooks say: how GPs diagnose coronary heart disease. Fam Pract. 2007;24:622-7.

6. Gardner K, Chapple A. Barriers to referral in patients with angina: qualitative study. BMJ. 1999;319:418-21.

7. Turnipseed SD, Trythall WS, Diercks DB, Laurin EG, Kirk JD, Smith DS, et al. Frequency of acute coronary syndrome in patients with normal electrocardiogram performed during presence or absence of chest pain. Acad Emerg Med. 2009;16:495-9.

8. Rutten FH, Kessels AG, Willems FF, Hoes AW. Electrocardiography in primary care; is it useful? Int J Cardiol. 2000;74:199-205.

9. Roffi M, Patrono C, Collet JP, Mueller C, Valgimigli M, Andreotti F, et al. 2015 ESC guidelines for the management of acute coronary syndromes in patients presenting without persistent ST-segment elevation: task force for the Management of Acute Coronary Syndromes in patients presenting without persistent ST-segment elevation of the European Society of Cardiology (ESC). Eur Heart J. 2016;37:267-315.

10. Goodacre S, Cross E, Arnold J, Angelini K, Capewell S, Nicholl J. The health care burden of acute chest pain. Heart. 2005;91:229-30.

11. Epstein RM, Hadee T, Carroll J, Meldrum SC, Lardner J, Shields CG. "Could this be something serious?" reassurance, uncertainty, and empathy in response to patients' expressions of worry. J Gen Intern Med. 2007;22:1731-9.

12. Floyd MR, Lang F, McCord RS, Keener M. Patients with worry: presentation of concerns and expectations for response. Patient Educ Couns. 2005;57: 211-6.

13. Bruins Slot MH, Rutten FH, van der Heijden GJ, Doevendans PA, Mast EG, Bredero AC, et al. Diagnostic value of a heart-type fatty acid-binding protein (H-FABP) bedside test in suspected acute coronary syndrome in primary care. Int J Cardiol. 2013;168:1485-9.

14. Verdon F, Herzig L, Burnand B, Bischoff T, Pécoud A, Junod M, et al. Chest pain in daily practice: occurrence, causes and management. Swiss Med Wkly. 2008;138:340-7.

15. Bruyninckx R, Van den Bruel A, Hannes K, Buntinx F, Aertgeerts B. GPs' reasons for referral of patients with chest pain: a qualitative study. BMC Fam Pract. 2009:10:55. https://doi.org/10.1186/1471-2296-10-55.

16. Burman RA, Zakariassen E, Hunskaar S. Chest pain out-of-hours - an interview study of primary care physicians' diagnostic approach, tolerance of risk and attitudes to hospital admission. BMC Fam Pract. 2014;15:207. https://doi.org/10.1186/s12875-014-0207-4.

17. Schols AM, van Boekholt TA, Oversier LM, Dinant GJ, Cals JW. General practitioners' experiences with out-of-hours cardiorespiratory consultations: a qualitative study. BMJ Open. 2016;6:e012136. https://doi.org/10.1136/ bmjopen-2016-012136.

18. Burman RA, Zakariassen E, Hunskaar S. Acute chest pain - a prospective population based study of contacts to Norwegian emergency medical communication centres. BMC Emerg Med. 2011;11:9. https://doi.org/10. 1186/1471-227X-11-9.

19. Kramer L, Rabanizada N, Haasenritter J, Bosner S, Baum E, DonnerBanzhoff $N$. Do guidelines on first impression make sense? Implementation of a chest pain guideline in primary care: a systematic evaluation of acceptance and feasibility. BMC Fam Pract. 2011;12:128. https://doi.org/10.1186/1471-2296-12-128.

20. Harbison J, Hossain O, Jenkinson D, Davis J, Louw SJ, Ford GA. Diagnostic accuracy of stroke referrals from primary care, emergency room physicians, and ambulance staff using the face arm speech test. Stroke. 2003;34:71-6.

21. Calnan M, Payne S, Kemple T, Rossdale M, Ingram J. A qualitative study exploring variations in GPs' out-of-hours referrals to hospital. Br J Gen Pract. 2007;57:706-13.

22. Rossdale M, Kemple T, Payne S, Calnan M, Greenwood R. An observational study of variation in GPs' out-of-hours emergency referrals. Br J Gen Pract. 2007:57:152-4

23. Canto JG, Goldberg RJ, Hand MM, Bonow RO, Sopko G, Pepine CJ, et al. Symptom presentation of women with acute coronary syndromes: myth vs reality. Arch Intern Med. 2007;167:2405-13.

24. Dey S, Flather MD, Devlin G, Brieger D, Gurfinkel EP, Steg PG, et al. Sexrelated differences in the presentation, treatment and outcomes among patients with acute coronary syndromes: the global registry of acute coronary events. Heart. 2009;95:20-6.
25. Bosner S, Haasenritter J, Hani MA, Keller H, Sönnichsen AC, Karatolios K, et al. Gender bias revisited: new insights on the differential management of chest pain. BMC Fam Pract. 2011;12:45. https://doi.org/ 10.1186/1471-2296-12-45.

26. Degano IR, Salomaa V, Veronesi G, Ferriéres J, Kirchberger I, Laks T, et al. Twenty-five-year trends in myocardial infarction attack and mortality rates, and case-fatality, in six European populations. Heart. 2015;101:1413-21.

27. Roger VL, Weston SA, Gerber Y, Killian JM, Dunlay SM, Jaffe AS, et al. Trends in incidence, severity, and outcome of hospitalized myocardial infarction. Circulation. 2010;121:863-9.

28. Summerton N. Making a diagnosis in primary care: symptoms and context. Br J Gen Pract. 2004;54:570-1.

29. Gill CJ, Sabin L, Schmid CH. Why clinicians are natural bayesians. BMJ. 2005: 330(7499):1080-3.

30. Howick J, Cals JW, Jones C, Price CP, Plüddemann A, Heneghan C, et al. Current and future use of point-of-care tests in primary care: an international survey in Australia, Belgium, the Netherlands, the UK and the USA. BMJ Open. 2014;4:e005611. https://doi.org/10.1136/bmjopen2014-005611.

31. Ayerbe L, Gonzalez E, Gallo V, Coleman CL, Wragg A, Robson J. Clinical assessment of patients with chest pain; a systematic review of predictive tools. BMC Cardiovasc Disord. 2016;16:18. https://doi.org/10. 1186/s12872-016-0196-4.

32. Fuat A, Hungin AP, Murphy JJ. Barriers to accurate diagnosis and effective management of heart failure in primary care: qualitative study. BMJ. 2003:326:196.

33. Stolper E, van Bokhoven M, Houben P, Van Royen P, Van de Wiel M, Van der Weijden $T$, et al. The diagnostic role of gut feelings in general practice a focus group study of the concept and its determinants. BMC Fam Pract. 2009;10:17. https://doi.org/10.1186/1471-2296-10-17.

34. Bruyninckx R, Van den Bruel A, Aertgeerts B, Van Casteren V, Buntinx F. Half of the patients with chest pain that are urgently referred are transported in unsafe conditions. Eur J Emerg Med. 2008;15:330-3.

35. Pique-Gilart M, Torres-Puig-Gros J, Balsera-Garrido B, Tarruella-Vidal I, Loscos-Solé J, Pueo-Crespo E, et al. The effectiveness of training schemes in the treatment of acute coronary syndrome at health centers. Med Int. 2008;32:3-7.

36. Bosner S, Haasenritter J, Abu Hani M, Keller H, Sönnichsen AC, Karatolios K, et al. Accuracy of general practitioners' assessment of chest pain patients for coronary heart disease in primary care: cross-sectional study with followup. Croat Med J. 2010;51:243-9.

37. Kip MMA, Noltes AM, Koffijberg H, MJ IJ, Kusters R. Improving early exclusion of acute coronary syndrome in primary care: the added value of point-of-care troponin as stated by general practitioners. Prim Health Care Res Dev. 2017;18:386-97.

\section{Ready to submit your research? Choose BMC and benefit from:}

- fast, convenient online submission

- thorough peer review by experienced researchers in your field

- rapid publication on acceptance

- support for research data, including large and complex data types

- gold Open Access which fosters wider collaboration and increased citations

- maximum visibility for your research: over $100 \mathrm{M}$ website views per year

At BMC, research is always in progress.

Learn more biomedcentral.com/submissions 